\title{
Prevalence of asthma-triggering drug use in adults and its impact on asthma
}

\section{control: A cross-sectional study - Saudi (Jeddah)}

Moufag Mohammed Saeed Tayeb¹, Mohammed Abdullah M Aldini², Azzam Khalid A Laskar2,

Ibrahim Ahmed M Alnashri², Sultan Khalid A Abdullah², Abdullah Hussaen A Almalki², Ahmad Ayed

A Derham², Turki Mohammed M Alotaibi², and Anas Muwaffaq Tayeb ${ }^{3}$

1. Department of Family Medicine, Faculty of Medicine, Jeddah University, Saudi Arabia

2. King Abdulaziz University, Jeddah, Saudi Arabia

3. Umm Al-Qura University, Makkah, Saudi Arabia

\section{RESEARCH}

Please cite this paper as: Tayeb MMS, Aldini MAM, Laskar AKA, Alnashri IAM, Abdullah SKA, Almalki AHA, Derham AAA, Alotaibi TMM, Tayeb AM. Prevalence of asthmatriggering drug use in adults and its impact on asthma control: A cross-sectional study - Saudi (Jeddah). AMJ 2017;10(12):1003-1007.

https://doi.org/10.21767/AMJ.2017.3220

\section{Corresponding Author:}

Moufag Mohammed Saeed Tayeb

Consultant, Associate Professor, Family Medicine

Faculty of Medicine, Jeddah University

Saudi Arabia

Email: moufagta@yahoo.com

\section{ABSTRACT}

\section{Background}

The use of asthma-triggering drugs (ATDs) is a major factor in poor asthma control (PAC), which can be either uncontrolled or partially controlled. ATDs include angiotensin-converting enzyme (ACE) inhibitors, $\beta$-blockers, aspirin, and nonsteroidal anti-inflammatory drugs (NSAIDs).

\section{Aims}

To measure the prevalence of ATD use in adult asthmatics and their control levels.

\section{Methods}

This is a one-year cross-sectional study (starting March 2016). A sample of 173 adult asthmatics (mean age: $44 \pm 16$ years) was enrolled from five primary care centres in Jeddah city (Saudi Arabia). Asthmatics were clinically diagnosed according to the British Thoracic Society's asthma guidelines. Chronic obstructive pulmonary disease was excluded by reversibility (i.e., symptom improvement after using asthma drugs). The four questions about asthma control from the Global Initiative for Asthma's 2016 guidelines were translated to Arabic, photos and names of ATDs available in local pharmacies were collected, and a questionnaire was drafted. The questionnaire was presented to adult asthmatics by medical students during a personal interview. Data were statistically analysed using SPSS.

\section{Results}

Fifty percent of the adult asthmatics who used ATDs had badly controlled asthma: 31 per cent uncontrolled and 19 per cent partially controlled. Of the patients who took ATDs, 97 per cent had used several ATDs for extended periods of time without any warnings from health professionals. In order of prevalence, aspirin, ACE inhibitors, other NSAIDs, and $\beta$-blockers were the most common ATDs used.

\section{Conclusion}

ATDs are a major cause of PAC. ATD use is extensive and often goes unnoticed. The present findings highlight the low awareness of health professionals about the undesirable effects of ATDs on asthma control. This problem needs to be resolved by regular and continuous asthma health educational courses. During clinic visits, health professionals should inquire about ATD use, discontinue them, and offer an alternative. This simple action could markedly improve asthma control.

\section{Keywords}

Asthma-triggering drugs, cardinal asthma, chest wheeze 


\section{What this study adds:}

\section{What is known about this subject?}

Certain drugs can trigger asthma attacks and contribute to bad control. These include aspirin, NSAIDs, ACE inhibitors, and $\beta$-blockers.

\section{What new information is offered in this study?}

Notably, there is a high prevalence of adult asthmatics with bad control who continue to use asthma-triggering drugs without any advice from health professionals.

3. What are the implications for research, policy, or practice?

There is an urgent need to educate health professionals about the effects of asthma-triggering drugs on its control, and to implement avoiding these drugs in practice.

\section{Background}

Asthma is a chronic inflammatory airway disease, clinically presented as a long-term recurrent chest symptom. The cardinal asthma symptoms are shortness of breath, wheeze, cough, and chest tightness. These symptoms are typically aggravated by certain environmental triggers, such as smoking, house dust mites, moulds, insects and other animals, pollens, foods, and drugs. ${ }^{1}$

In addition to the cardinal symptoms, there are other diagnostic criteria for adult asthma. These include a positive family history of asthma or other allergic diseases, presence of other concurrent allergic diseases, improvement of asthma symptoms after taking asthma medications, as well as the presence of chest wheeze detected by a physician in clinic. $^{2}$

There are three levels of asthma control: controlled, partially controlled, and uncontrolled. Four main questions in the Global Initiative for Asthma (GINA) 2016 guidelines can be used to clarify the level of asthma control of a patient by studying the recurrence of symptoms over the last month. The questions focus on the frequency of daytime asthma symptoms, B2 agonist use per week, and presence of any nocturnal asthma symptoms or activity limitations. A health professional's main aim is to keep a patient's asthma well controlled. ${ }^{3}$

Specific drugs can trigger asthma, reducing control, and should therefore be avoided by asthmatics. However, many adult asthmatics still use these asthma-triggering drugs (ATDs) because they lack guidance from their health professionals, even during clinic visits. In many cases, the use of ATDs can continue unnoticed for years, despite poor asthma control (PAC). These drugs include aspirin, angiotensin-converting enzyme (ACE) inhibitors, other nonsteroidal anti-inflammatory drugs (NSAIDs), and $\beta$ blockers. $^{4}$

\section{Methods}

This cross sectional study was conducted in five primary care centres in Jeddah city, Saudi Arabia. The sample size was 173 asthmatic adults: 103 men and 70 women. Asthma was clinically diagnosed using the patient's history and according to the British Thoracic Society's 2016 guidelines. Chronic obstructive pulmonary disease was excluded using a reversibility test (25 per cent improvement in peak flow readings before and after two puffs of salbutamol). This study was conducted from March 2016 to March 2017 and consisted of a questionnaire presented by medical students from two universities in the western region of Saudi. The questionnaire was presented to patients during a personal interview.

The GINA 2016 guidelines were the source of the four main questions included in the questionnaire, which were designed to assess the patient's level of asthma control. These questions were translated into Arabic. From the patient's answers, their level of asthma control was defined.

In addition to these questions, drugs that trigger asthma attacks were included in the questionnaire (both generic and scientific names). Photographs of these drugs were collected from the internet and by visiting local pharmacies to collect the most popular forms of these drugs in the Saudi market. These drug photographs were presented to the patients along with the questionnaire for recognition purposes. The drug families included in the questionnaire were ACE inhibitors, $\beta$-blockers, aspirin, and NSAIDs. ${ }^{5}$

Information collected in the questionnaires was transferred to the SPSS statistical system under three levels of asthma control: controlled, partially controlled and uncontrolled. The number of ATDs used was determined for each patient. Subsequently, the level of asthma control was correlated with the number of ATDs.

\section{Results}

The sample population was almost equally divided between age groups, however there was a larger percentage of patients between 36 and 55 years old. There were 103 females (60 per cent) and 70 males (40 per cent) (Table 1). 
Most of the adult asthmatics who visited primary care in this study had either uncontrolled (63 per cent) or partially controlled (34 per cent) asthma, while only a minority had controlled asthma (3 per cent) (Table 2 ).

Fifty-one per cent of the adult asthmatics in this study were found to take ATDs. Most of them were either in the uncontrolled (31 per cent) or partially controlled (19 per cent) groups, while the controlled group was only a minority (2 per cent). Alternatively, 49 per cent of the adult asthmatics did not use ATDs. Of these, 32 per cent were in the uncontrolled group, 15 per cent in the partially controlled group, and 2 per cent in the controlled group. This may indicate PAC because of causes other than ATDs (Table 3).

Interestingly, the adult asthmatics in this study tended to use several ATDs concurrently. Uncontrolled asthmatics (64 per cent) and partially-controlled asthmatics (33 per cent) used four ATDs on average, while controlled asthmatics used three (Table 4$)^{6}$

In order of prevalence, aspirin, ACE inhibitors, other NSAIDs, and $\beta$-blockers were the most common ATDs used. Uncontrolled asthmatics used mainly aspirin, Capoten (captopril), Voltaren (diclofenac sodium), and Concor (bisoprolol). Partially controlled asthmatics also mostly used aspirin, but used Brufen (profinal) rather than diclofenac sodium, and Coversyl (perindopril) rather than captopril (Table 5).

\section{Discussion}

To our knowledge, this is the first cross-sectional study that correlates asthma control and ATDs. However, ATD use continues in asthmatics despite the contraindications. $\beta$ blockers are contraindicated in asthmatics, while the more selective types are relatively contraindicated. Aspirin and NSAIDs are relatively contraindicated in asthmatics, particularly if they have nasal polyps. However, single doses of diclofenac sodium in asthmatic children does not seem to cause bronchospasms. ACE inhibitors mainly cause coughing, but may also occasionally trigger bronchospasms. $^{5}$

Many factors can cause PAC, one of which is ATD use. However, asthmatic adults often use these drugs widely for many years without knowing the risks because no health professional advises them otherwise. This can be a critical cause of PAC, emergency room visits, and continuous asthma morbidity. ${ }^{7}$
The present findings reflect the unacceptably low awareness of health professionals about the harmful effects of ATDs on asthma control levels. Regular asthma educational courses to health professionals would be an effective strategy to improve this awareness. These courses should include all workers having adult asthma, such as general practitioners, educators, and nurses. It is especially vital to educate nurses because they are often in direct contact with adult asthmatics.

The harmful effects of PAC because of ATDs can be severe, causing continuous morbidity, poor productivity, and frequent absence from work, as well as frequent visits to outpatient clinics and emergency rooms. The financial burden on asthmatics and health systems must also be considered. $^{8}$

The role of primary care in the successful treatment of asthma is significant. As many as 80 per cent of asthmatics rely on primary care professionals, whereas only a minority of asthmatics visit specialists. Asthmatics often forget to bring their medicines to the clinic, which is a challenge. During each clinical visit, primary care physicians and nurses should clearly ask adult asthmatics about all drugs used orally, reminding them to bring them along in future if they forget. Many cases of ATD use can be discovered and prevented by following this simple procedure. ${ }^{9}$

ATDs are used to treat many major critical diseases, such as hypertension, ischemic heart disease, joint pain, and osteoarthritis. Stopping ATD use and replacing them with alternative drugs with the same properties but no asthmatriggering effects, or with more selective drugs will prevent harmful effects and improve the asthma control of many asthmatics. $^{10}$

An oral alternative to aspirin is clopidogrel (Plavix), which is an antiplatelet drug that reduces stroke and cardiac diseases. ACE inhibitors and $\beta$-blockers can be replaced by calcium channel blockers or diuretics. NSAIDs can be swapped for paracetamol or muscle relaxants. ${ }^{11}$

\section{Conclusion}

ATD use is a substantial cause of PAC. This reflects the low awareness of health professionals about the negative effects of these drugs on asthma control. This issue which can be solved by regular asthma health education. Health professionals should ask adult asthmatics clearly about their use of ATDs and remind them to bring their medications along to the clinic for assessment. Any ATD use should be 
stopped and an alternative must be provided. This simple process can easily improve asthma control.

\section{References}

1. Mims JW. Asthma: definitions and pathophysiology. Int Forum Allergy Rhinol. 2015;5:S1.

2. British Thoracic Society Asthma Guideline Quick Reference Guide 2016.

3. Global Initiative for Asthma Guideline (GINA). Pocket guide for asthma management and prevention 2017.

4. Covar RA, Macomber BA, Szefler SJ. Medications as asthma triggers. Immunol Allergy Clin North Am. 2005;25(1):169-90.

5. Sanfiorenzo C, Pipet A. Exacerbations of asthma-precipitating factors: drugs. Rev Mal Respir. 2011;28(8):1059-70.

6. Craig T Richerson HB, Moeckli J. Problem drugs for the patient with asthma. Compr Ther. 1996;22(6):339-44.

7. Gallefoss F, Bakke PS. Impact of patient education and self-management on morbidity in asthmatics. Respir Med. 2000;94(3):279-87.

8. Peters SP, Ferguson G, Deniz $Y$, et al. Uncontrolled asthma: A review of the prevalence, disease burden and options for treatment. Respir Med. 2006;100(7):113951.

9. Cross $S$, Buck $S$, Hubbard J. ABC of allergies: Allergy in general practice. BMJ. 1998;316(7144):1584.

10. Covar RA, Macomber BA, Szefler SJ. Medications as asthma triggers. Immunol Allergy Clin North Am. 2005;25(1):169-90.

11. Pongdee T. Medications may trigger asthma symptoms. American Academy of Allergy Asthma, Immunology (AAAAI).

\section{PEER REVIEW}

Not commissioned. Externally peer reviewed.

\section{CONFLICTS OF INTEREST}

The authors declare that they have no competing interests.

\section{FUNDING}

None
Table 1: Demographic distribution of adult asthmatic population sample ( $n=173$ patients)

\begin{tabular}{|c|c|c|c|}
\hline Age Groups & Male & Female & Total \\
\hline$<26$ & 18 & 15 & 33 \\
\hline $26-35$ & 10 & 15 & 25 \\
\hline $36-45$ & 12 & 26 & 38 \\
\hline $46-55$ & 12 & 25 & 37 \\
\hline $56-65$ & 10 & 13 & 23 \\
\hline$>65$ & 9 & 9 & 18 \\
\hline Total & 71 & 103 & 174 \\
\hline
\end{tabular}

Table 2: Control levels in adult asthmatics visiting primary care ( $n=173$ patients)

\begin{tabular}{|c|c|c|c|}
\hline Gender & Controlled & $\begin{array}{c}\text { Partially } \\
\text { Controlled }\end{array}$ & Uncontrolled \\
\hline Male & 1 & 32 & 38 \\
\hline Female & 5 & 27 & 74 \\
\hline Total & 6 & 59 & 112 \\
\hline$\%$ & 3 & 34 & 63 \\
\hline
\end{tabular}

Table 3: Use of ATDs in adult asthmatics at different levels of control ( $n=173$ patients)

\begin{tabular}{|c|c|c|}
\hline \multirow{2}{*}{ Control Level } & \multicolumn{2}{|c|}{ Numbers of Drugs Taken } \\
\cline { 2 - 3 } & None & Taking 1-4 drugs \\
\hline Controlled & $3(2 \%)$ & $2(1 \%)$ \\
\hline Partially Controlled & $26(15 \%)$ & $31(19 \%)$ \\
\hline Uncontrolled & $58(32 \%)$ & $54(31 \%)$ \\
\hline$\%$ & $49 \%$ & $51 \%$ \\
\hline
\end{tabular}

Table 4: Number of ATDs taken in relation to asthma control level

\begin{tabular}{|c|c|c|}
\hline \multirow{2}{*}{ Control Level } & \multicolumn{2}{|c|}{ Number of Drugs Taken } \\
\cline { 2 - 3 } & Count & Maximum \\
\hline Controlled & $5(3 \%)$ & 3 \\
\hline Partially Controlled & $57(33 \%)$ & 4 \\
\hline Uncontrolled & $112(64 \%)$ & 4 \\
\hline
\end{tabular}

\section{ETHICS COMMITTEE APPROVAL}

Directorate of Health Affairs, Jeddah, Ministry of Health, Saudi Arabia 
Table 5: Asthma control levels vs. names of ATDs used

\begin{tabular}{|c|c|c|c|}
\hline & Level & Drug Name & $\begin{array}{c}\text { Number of patients } \\
\text { using }\end{array}$ \\
\hline \multirow{32}{*}{ 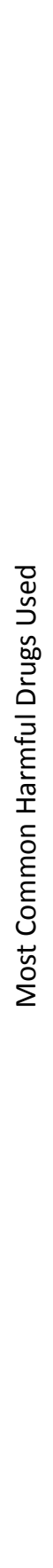 } & \multirow{5}{*}{ 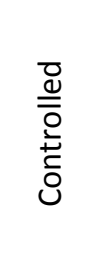 } & Beta-Adalat (Atenolo) & 1 \\
\hline & & Voltaren (Diclofenac Sodium) & 1 \\
\hline & & Cozaar (Losartan) & 1 \\
\hline & & Aspirin (Aspirin) & 1 \\
\hline & & Arthrotec (Diclofenac Sodium/Misoprostol) & 1 \\
\hline & \multirow{9}{*}{ 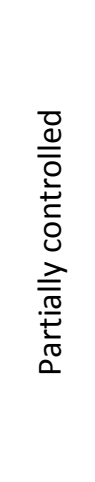 } & Aspirin (Aspirin) & 6 \\
\hline & & Profinal (Ibuprofen) & 4 \\
\hline & & Coversyl (Perindopril) & 4 \\
\hline & & Roxonin (Loxoprofen) & 4 \\
\hline & & Concor (Bisoprolol) & 3 \\
\hline & & Mobic (Meloxicam) & 2 \\
\hline & & Rofenac (Diclofenac sodium) & 2 \\
\hline & & Voltaren (Diclofenac sodium) & 2 \\
\hline & & Biscor (Bisoprolol) & 2 \\
\hline & \multirow{18}{*}{ 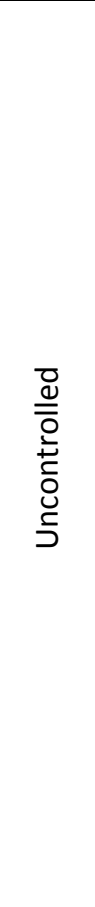 } & & \\
\hline & & Aspirin (Aspirin) & 11 \\
\hline & & Capoten (Captopril) & 8 \\
\hline & & Voltaren (Diclofenac Sodium) & 5 \\
\hline & & Concor (Bisoprolol) & 4 \\
\hline & & Coversyl (Perindopril) & 4 \\
\hline & & Aspricard (Aspirin) & 4 \\
\hline & & Celebrex (Celecoxib) & 4 \\
\hline & & Divido (Diclofenac Sodium) & 4 \\
\hline & & Profinal (Ibuprofen) & 3 \\
\hline & & Voltaren Retard (Diclofenac Sodium) & 3 \\
\hline & & Brufen (Ibuprofen) & 3 \\
\hline & & Beta-Adalat (Atenolo) & 2 \\
\hline & & Jusprin (Aspirin) & 2 \\
\hline & & Mobic (Meloxicam) & 2 \\
\hline & & Roferac (Diclofenac Sodium) & 2 \\
\hline & & Cozaar (Losartan) & 2 \\
\hline & & Cardex (Bisoprolol) & 2 \\
\hline
\end{tabular}

